\title{
BMJ Global Health Estimating maternal mortality: what have we learned from 16 years of surveys in Afghanistan?
}

\author{
Sandra Alba (1) , ${ }^{1}$ Egbert Sondorp (1) , ${ }^{1}$ Elisabeth Kleipool, ${ }^{1}$ Rajpal Singh Yadav, ${ }^{1}$ \\ Arab S Rahim, ${ }^{1}$ Konrad T Juszkiewicz, ${ }^{1}$ Gilbert Burnham ${ }^{2}$
}

To cite: Alba S, Sondorp E, Kleipool E, et al. Estimating maternal mortality: what have we learned from 16 years of surveys in Afghanistan?BMJ Global Health 2020;5:e002126. doi:10.1136/ bmjgh-2019-002126

Handling editor Seye Abimbola

- Additional material is published online only. To view, please visit the journal online (http://dx.doi.org/10.1136/ bmjgh-2019-002126).

Received 29 October 2019 Revised 2 March 2020 Accepted 7 March 2020
Check for updates

(c) Author(s) (or their employer(s)) 2020. Re-use permitted under CC BY. Published by BMJ.

${ }^{1}$ KIT Royal Tropical Institute, Amsterdam, The Netherlands 2Johns Hopkins University Bloomberg School of Public Health, Baltimore, Maryland, USA

\section{Correspondence to}

Dr Sandra Alba; s.alba@kit.nl

\section{INTRODUCTION}

'Particularly hard hit by Afghanistan's 23 years of war, civil strife and Taliban misrule are Afghan women, who are experiencing what health officials call "catastrophic" death rates associated with pregnancy and childbirth'. ${ }^{1}$ The opening paragraph of this 2002 New York Times article captures how women's health became, and still is, a cornerstone of development aid in Afghanistan. As a result, maternal health measurements have become an important tool for 'evidence-based advocacy', ${ }^{2}$ as in many other countries grappling with poor maternal health. Maternal mortality estimates in particular, have played a major role in justifying external assistance to the Afghan healthcare system ${ }^{1}$ and in documenting maternal health improvements as a legacy of the 2001 intervention and successive foreign involvement in the country. ${ }^{3}$

Sixteen years later, we released the results of the Afghanistan Health Survey (AHS) 2018. ${ }^{4}$ It was the second nationally representative survey conducted within the frame of System Enhancement for Health Action in Transition (SEHAT),${ }^{5}$ a service delivery and health systems strengthening project implemented between 2015 and 2018. SEHAT was managed by the Afghan Ministry of Public Health and financed by the World Bankadministered Afghanistan Reconstruction Trust Fund, with the World Bank, European Union, USA and Canada as major donors. KIT Royal Tropical Institute, based in the Netherlands, was selected as the third-party monitor for SEHAT and was responsible for the implementation of two AHSs in 2015 and 2018. The SEHAT monitoring and evaluation framework had a strong focus on maternal and child health ${ }^{5}$ and included maternal mortality. Despite considerable efforts to measure maternal mortality in
Summary box

- Maternal mortality is notoriously difficult to measure because even in high-mortality areas maternal deaths are relatively rare. These difficulties are further compounded in low-income and conflictaffected settings such as Afghanistan.

- Between 2002 and 2018, maternal mortality estimates for Afghanistan have been provided by six surveys, using a variety of costly methodologies yet yielding contradictory and sometimes implausible results.

- The 'failure' of household surveys to provide robust data on maternal mortality in Afghanistan is a call to reconsider the value of maternal mortality measurements to assess safe motherhood interventions in low-income and conflict-affected settings.

- We encourage stakeholders involved in the commissioning and use of maternal mortality estimates in Afghanistan and similar contexts to take stock of experiences so far and carefully consider how to best make use of existing resources.

- In the short-term efforts to measure improvements in maternal health should be redirected towards measurements of access, use and quality of services for pregnant women and women giving birth, with longer-term investments towards civil registration as a source of robust maternal mortality data.

both surveys, we did not include any estimates in either of the final reports due to concerns about their validity.

In this commentary, we contextualise our experience within the history of previous efforts to measure maternal mortality in Afghanistan. We review our own lessons learnt and reflect, more globally, on their implications. We argue that our Afghanistan case-specific experience exemplifies the wellknown shortcomings of surveys to measure maternal mortality and should act as a call to reconsider its value in assessing safe motherhood interventions in Afghanistan and other low-income and conflict-affected settings. 
Table 1 Overview of survey methodologies

\begin{tabular}{|c|c|c|c|c|c|}
\hline Survey & $\begin{array}{l}\text { Survey } \\
\text { year }\end{array}$ & Recall period & Sampling & $\begin{array}{l}\text { Method of } \\
\text { estimation }\end{array}$ & Organisations responsible \\
\hline RAMOS $1^{910}$ & 2002 & $\begin{array}{l}3 \text { years prior to the } \\
\text { survey }\end{array}$ & $\begin{array}{l}\text { Women of reproductive age (15-49 years) } \\
13848 \text { households } \\
\text { Four selected districts in four provinces: Kabul city, } \\
\text { Kabul province (urban); Alisheng district, Laghman } \\
\text { province (semirural); Maywand, Kandahar province } \\
\text { (rural); and Ragh, Badakshan province (rural, most } \\
\text { remote). }\end{array}$ & $\begin{array}{l}\text { Verbal } \\
\text { autopsies }\end{array}$ & $\begin{array}{l}\text { Funding: UNICEF, CDC and } \\
\text { USAID } \\
\text { Implementation: CDC, UNICEF } \\
\text { and MoPH }\end{array}$ \\
\hline RAMOS $2^{14}$ & 2011 & $\begin{array}{l}3 \text { years prior to the } \\
\text { survey }\end{array}$ & $\begin{array}{l}\text { Women of reproductive age ( } 15-49 \text { years) } \\
25043 \text { households } \\
\text { Urban area of Kabul city and the rural area of Ragh, } \\
\text { Badakhshan }\end{array}$ & $\begin{array}{l}\text { Verbal } \\
\text { autopsies }\end{array}$ & $\begin{array}{l}\text { Funding: USAID } \\
\text { Implementation: Johns Hopkins } \\
\text { Bloomberg School of Public } \\
\text { Health and MoPH }\end{array}$ \\
\hline $\mathrm{DHS}^{13}$ & 2015 & $\begin{array}{l}7 \text { years prior to the } \\
\text { survey }\end{array}$ & $\begin{array}{l}\text { Women of reproductive age (15-49 years) } \\
22351 \text { households } \\
\text { Nationally representative }\end{array}$ & $\begin{array}{l}\text { Sisterhood } \\
\text { method }\end{array}$ & $\begin{array}{l}\text { Funding: USAID } \\
\text { Implementation: CSO, MoPH } \\
\text { and ICF }\end{array}$ \\
\hline $\mathrm{AHS}^{4}$ & 2018 & $\begin{array}{l}3 \text { years prior to the } \\
\text { survey }\end{array}$ & $\begin{array}{l}\text { Women of reproductive age (15-49 years) } \\
19684 \text { households } \\
\text { Nationally representative }\end{array}$ & $\begin{array}{l}\text { Verbal } \\
\text { autopsies }\end{array}$ & $\begin{array}{l}\text { Funding: World Bank/MoPH } \\
\text { Implementation: KIT Royal } \\
\text { Tropical Institute and CSO }\end{array}$ \\
\hline
\end{tabular}

AHS, Afghanistan Health Survey; AMS, Afghan Mortality Survey; CSO, Central Statistics Organisation; DHS, Demographic and Health Survey; EMRO, Eastern Mediterranean Regional Office; MoPH, Ministry of Public Health; RAMOS, Reproductive Age Mortality Survey; USAID, United States Agency for International Development.

\section{HISTORICAL OVERVIEW}

The maternal mortality ratio (MMR) is defined as the number of maternal deaths during a given time period per 100000 live births during the same time period. ${ }^{6}$ Maternal mortality is notoriously difficult to measure because even in high-mortality areas maternal deaths are relatively rare. Challenges broadly fall into two categories $^{7}$ : (1) problems differentiating between deaths due to the pregnancy as opposed to merely happening during the pregnancy (the latter being measured by the pregnancyrelated mortality ratio and (2) problems finding deaths, particularly encountered in settings such as Afghanistan, where geography and security can severely hinder access to households.

Between 2002 and 2018, maternal mortality estimates for Afghanistan have been provided by six surveys funded by external donors (primarily United States Agency for International Development and the World Bank) and implemented by or in close collaboration with international institutions (table 1 and figure 1). The surveys used a variety of costly methodologies yielding sometimes contradictory and implausible results. The estimates vary from 6507 deaths per 100000 births in Ragh in 2002 to 153 nationally in 2018. UNICEF cut-offs ${ }^{8}$ help put this in perspective: MMR values above 1000 are considered extremely high and are only reported nationally in a few sub-Saharan countries, while countries neighbouring Afghanistan have low (MMR below 300) or very low
(MMR below 100) maternal mortality. While a decrease in maternal mortality is in line with UN Inter-agency Group's modelled estimates, ${ }^{6}$ the large variation between estimates, even between surveys conducted at the same time point (eg, 2015) is sobering.

The first MMR estimates produced for Afghanistan came from the Reproductive Age Mortality Survey (RAMOS) 1 study in 2002. The study reported a national estimate of 1600 deaths per 100000 live births and four subnational estimates, ranging from 418 in Kabul to 6507 in Ragh. ${ }^{910}$ These widely quoted estimates sparked off the key focus on maternal mortality in policy and planning for Afghanistan. ${ }^{1311}$ Set against the values, the AMS 2010 results with an MMR of 327 were criticised as implausibly low and potentially jeopardising future investments in maternal health in the country. ${ }^{312}$ On the other hand, the DHS 2015 estimates with an MMR of 1291 was criticised for being too high. Although this likely overestimation was openly acknowledged in the DHS report, ${ }^{13}$ this estimate is still regularly quoted as the MMR for Afghanistan ${ }^{11}$ though with some reservations at times. ${ }^{12}$ In 2011, a second RAMOS study was conducted in two areas of Afghanistan. ${ }^{14}$ The study showed a large decrease in the MMR, but the MMR decrease in Ragh from 6507 to 713 does cast some doubts on the validity of the RAMOS estimates in general.

Against this backdrop, the two AHS estimates (276 in 2015 and 153 in 2018) were criticized for being too low. 


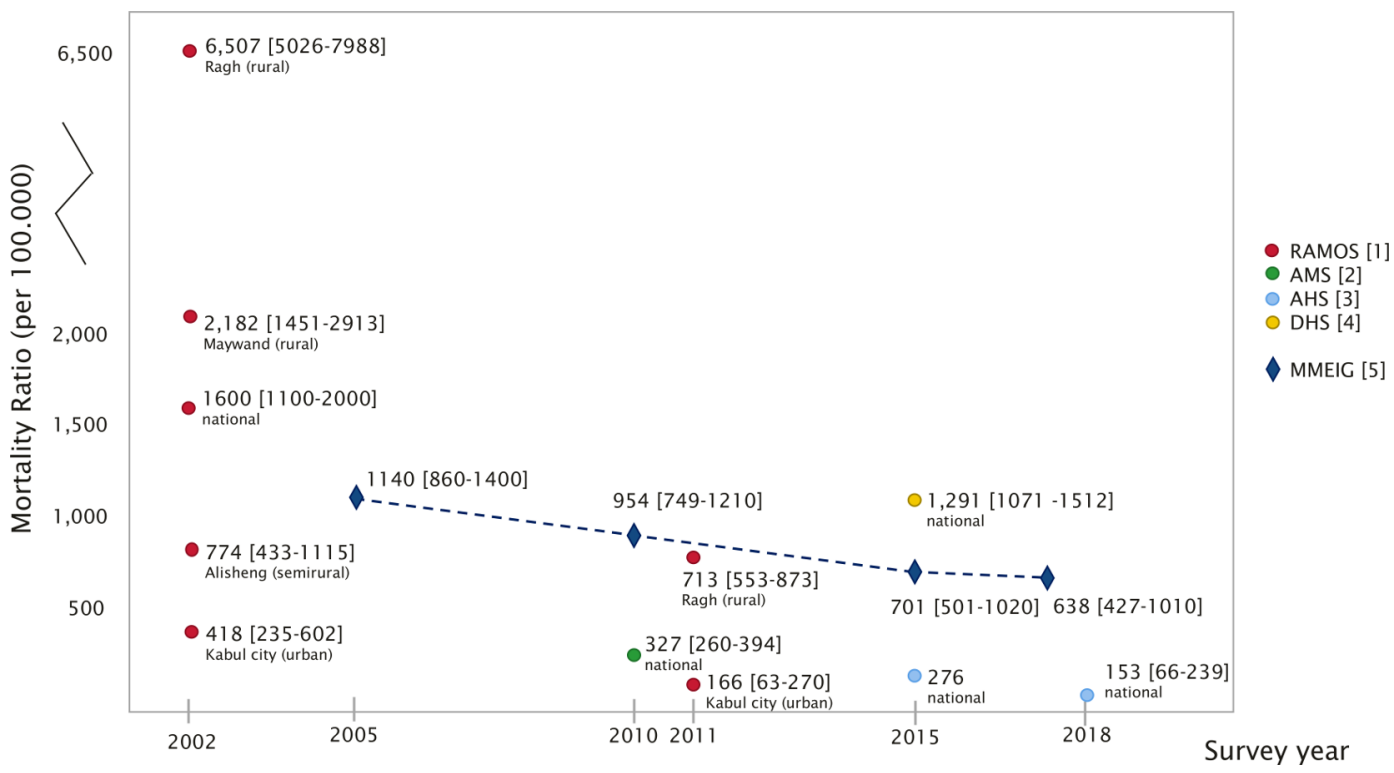

Figure 1 Maternal mortality estimates in Afghanistan from 2005 to 2018. (1) RAMOS, providing MMR estimates; (2) AMS, providing PRMR estimates; (3) AHS, providing MMR estimates; (4) DHS, providing PRMR estimates; (5) internationally comparable MMR estimates by the Maternal Mortality Estimation Inter-Agency Group, WHO, UNICEF, UNFPA, World Bank Group and the United Nations population division, providing MMR estimates. AHS, Afghanistan Health Survey; AMS, Afghan Mortality Survey; DHS, Demographic and Health Survey; MMR, maternal mortality ratio; PRMR, pregnancy-related mortality ratio; RAMOS, Reproductive Age Mortality Survey.

Concerns regarding the AHS estimates were founded on anomalies in data collection. We conducted further analyses in 2018 which confirmed the likely underestimation of the AHS 2018 MMR (see online supplementary file 1). Local policy makers heavily debated the publication of these estimates in the final AHS 2015 and AHS 2018 reports and ultimately neither report included them. To the best of our knowledge, the AHS estimates are not officially used by public health authorities in Afghanistan.

Despite the wide variation in MMR estimates over time, a descending trend can be discerned. This is in line with evidence of remarkable increases in access to care and coverage of several maternal care interventions (eg, antenatal care, skilled birth attendance and births in health facilities). ${ }^{415}$ These increases are in turn reflected in decreases in the UN Inter-agency Group estimates of maternal mortality (which rely on skilled birth attendance as a predictor in their models). ${ }^{6}$

\section{DOING THINGS RIGHT AND DOING THE RIGHT THINGS}

After over a decade of trial and error, the time has come to review lessons learnt before further attempts to estimate maternal mortality in Afghanistan. The triple-loop learning framework ${ }^{16}$ offers a useful structure for these reflections. Single-loop learning consists of identifying errors (Are we doing things right?). Double-loop learning goes a step further and questions methodologies and analytical frameworks (Are we doing the right things?). Finally, triple-loop learning is deeper questioning of purpose and legitimacy (Should we be doing anything at all?).

\section{Are we doing things right?}

Our review of AHS 2015 and AHS 2018 data and processes revealed that a number of deaths were probably missed. Following fears of data fabrication in hardto-access areas in 2015 , we significantly tightened quality control for theAHS 2018. This included (1) enlisting a team of external independent monitors (in addition to the internal monitors) to randomly revisit households and (2) rapid statistical review of selected data before data entry to ensure data credibility. Yet, in spite of these improvements, it appears that deaths were still underreported in 2018. This could be due to further issues in our survey operations. Indeed, we did not use fieldcheck tables, which could have helped to ensure internal consistency between births and related events for children and mothers. However, more profound reasons such as grief or shame may also be at play, ${ }^{17}$ leading to both under-reporting of all deaths or inaccurate reporting of maternal mortality as deaths from other causes.

In short, it is difficult to 'do things right' when measuring maternal mortality in Afghanistan. Survey implementers should therefore carefully design, implement and describe their quality assurance mechanisms so as to enable users to contextualise the magnitude of their maternal mortality estimates.

\section{Are we doing the right things?}

There is a reasonable consensus that surveys are not suited to measure statistically rare events such a maternal deaths. ${ }^{9}$ Civil registration and vital statistics (CRVS) information systems are hailed as the prime source of vital statistics, ${ }^{18}$ with sample surveys, censuses and 
modelled estimates common but imperfect alternatives. Yet Afghanistan, like many other low-income and middleincome countries, does not have adequate CRVS systems. Although the government revitalised vital events registration after the Taliban regime (in 2001) with the support of UNICEF and WHO, a recent report confirms that limited death registration takes place and causes of death are often not recorded accurately. ${ }^{19}$ Afghanistan set a fairly unambitious target of $20 \%$ registration by $2020,{ }^{19}$ showing that it is a long way from being able to rely on CVRS-based MMR estimates. On the other hand, the dual record system, a sentinel site approach to civil registration successfully implemented in India, ${ }^{20}$ may hold promise for Afghanistan and could pave the way towards strengthening national civil registration and national statistics.

In other words, the failure of household surveys to provide robust data on maternal mortality confirms that they are not 'the right thing'. However, it is not obvious what the right thing exactly is, especially in the short to medium term. Nevertheless, there is a strong case to strengthen national civil registration and national statistics in Afghanistan.

\section{Should we be doing anything at all?}

As has already been argued since the mid-1990s, the measurement of MMR using surveys is not a good use of scarce resources. ${ }^{21}$ This critique is based not only on measurement difficulties described previously but also on challenges to attribute any decreases (when discernible) to specific interventions. This logic resonates particularly in conflictaffected settings such as Afghanistan, where the ethical imperative to act is arguably stronger than the necessity to measure, especially if we cannot measure well. This critique is related to calls to focus on process indicators (such as access, use and quality of healthcare services) on the causal pathway towards decreased mortality, as has been done by a number of recent studies in Afghanistan. ${ }^{1522} 23$ These indicators are relatively easy to measure and more useful to inform country-level planning than the MMR, since they can also be disaggregated by equity variables. ${ }^{2}{ }^{12}$ These technical considerations fit into broader discussions on the political drivers of maternal mortality measurement. It has been argued that the scientific practice which emphasises maternal mortality measurement is driven by global accountability needs to monitor and justify donors' investments at the expense of governments' local programme planning needs and accountability towards constituents, for whom data on equitable access to care would be much more relevant. ${ }^{2}$

In summary, diverse calls question the usefulness of the MMR to monitor safe motherhood interventions, suggesting that perhaps we "should not be doing anything at all' to measure it in Afghanistan.

\section{CONCLUSION}

What have we learnt from 16 years of maternal mortality surveys in Afghanistan? Not much about actual mortality levels-though contextual evidence suggests they are declining-but enough to know that survey methodologies are not providing robust MMR estimates. While the arguments we presented are not new, the Afghanistan experience exemplifies the well-known shortcomings of surveys to measure maternal mortality, particularly exacerbated in fragile and conflict-affected settings. Before further efforts to measure maternal mortality are undertaken in Afghanistan, we encourage stakeholders involved in the commissioning and use of these estimates to take stock of experiences so far and to carefully consider how to best make use of existing resources. Based on our experience, we believe the time has come to temporarily halt attempts to measure maternal mortality in Afghanistan through surveys and to explore alternative methods. In the short term, efforts to measure improvements in maternal health should be redirected towards measurements of availability, access and quality of services for pregnant women and women giving birth, with a longerterm investments towards CRVS systems as a source of robust maternal mortality data.

Acknowledgements We are thankful to Han Raggers and Jan Bartlema for performing all demographic analyses for the AHS 2018 and AHS 2015 respectively, and insightful comments which have contributed to this manuscript. Many thanks also to Frouwke Veenstra for helping us better understand the shortcomings of the AHS 2015 mortality data and to Eelco Jacobs for reviewing the manuscript and suggesting important edits. We are very grateful to all staff of the Ministry of Public Health of Afghanistan as well as the National Statistics and Information Authority (formerly Central Statistical Organisation) involved for insightful discussions which helped generate the thoughts presented in this commentary.

Contributors SA drafted the first version of the manuscript based on discussions with ES, GB and EK. RSY, ASR and KTJ reviewed the manuscript and provided comments.

Funding The AHS 2015 and 2018 study was funded by the World Bank Group.

Competing interests None declared.

Patient consent for publication Not required.

Provenance and peer review Not commissioned; externally peer reviewed. Data availability statement No data are available.

Open access This is an open access article distributed in accordance with the Creative Commons Attribution 4.0 Unported (CC BY 4.0) license, which permits others to copy, redistribute, remix, transform and build upon this work for any purpose, provided the original work is properly cited, a link to the licence is given, and indication of whether changes were made. See: https://creativecommons.org/ licenses/by/4.0/.

\section{ORCID iDs}

Sandra Alba http://orcid.org/0000-0003-2435-624X

Egbert Sondorp http://orcid.org/0000-0003-2325-7266

\section{REFERENCES}

1 Miller J, Gall C. Women suffer most in Afghan health crisis, experts say. N. Y. times, 2002. Available: https://www.nytimes.com/2002/10/ 27/world/women-suffer-most-in-afghan-health-crisis-experts-say. html [Accessed 9 Jan 2020].

2 Storeng KT, Béhague DP. "Guilty until proven innocent": the contested use of maternal mortality indicators in global health. Crit Public Health 2017;27:163-76.

3 Nordland R. Reported gains in Afghan maternal health are found to be Implausible. N. Y. times, 2015. Available: https://www.nytimes. com/2015/12/05/world/asia/afghanistan-maternal-mortality-rate. html [Accessed 7 Oct 2019].

4 Afghanistan Health Survey (AHS) 2018. RMNCAH Directorate | MoPH, 2019. Available: https://rmncah-moph.gov.af/blog/2019/03/ 02/ahs-2018/ [Accessed 7 Oct 2019]. 
5 The World Bank. Projects : Afghanistan: System Enhancement for Health Action in Transition Project |. Available: http://www.projects. worldbank.org/P129663/afghanistan-system-enhancement-healthaction-transition-project? lang=en [Accessed 7 Oct 2019]

6 WHO, UNICEF, UNFPA, World Bank Group, and United Nations Population Division, Maternal Mortality Estimation Inter-Agency Group. Maternal mortality in 1990-2015 - Afghanistan. Available: https://www.who.int/gho/maternal_health/countries/afg.pdf [Accessed 7 Oct 2019].

7 Graham WJ, Foster LB, Davidson L, et al. Measuring progress in reducing maternal mortality. Best Pract Res Clin Obstet Gynaecol 2008;22:425-45.

8 Maternal mortality. Unicef data. Available: https://data.unicef.org/ topic/maternal-health/maternal-mortality/ [Accessed 28 Jan 2020].

9 Bartlett L, Whitehead S, Crouse C. Maternal Mortality in Afghanistan: Magnitude, Causes, Risk Factors and Preventability - Summary of findings, 2002. Available: https://reliefweb.int/report/afghanistan/ afghanistan-among-worst-places-globe-womens-health-say-unicefand-cdc [Accessed 7 Oct 2019].

10 Bartlett LA, Mawji S, Whitehead S, et al. Where giving birth is a forecast of death: maternal mortality in four districts of Afghanistan, 1999-2002. Lancet 2005;365:864-70.

11 Britten S. Maternal mortality in Afghanistan: setting achievable targets. Lancet 2017;389:1960-2.

12 World Health Organization. WHO country cooperation strategy at a glance: Afghanistan. CCS brief Afghanistan, 2018. Available: https:// apps.who.int/iris/handle/10665/136852 [Accessed 10 Jan 2020].

13 Central statistics organization (CSO), Ministry of public health (MoPH), and ICF. Afghanistan demographic and health survey 2015. Kabul. Afghanistan 2017 https://dhsprogram.com/pubs/pdf/FR323/ FR323.pdf

14 Bartlett L, LeFevre A, Zimmerman L, et al. Progress and inequities in maternal mortality in Afghanistan (RAMOS-II): a retrospective observational study. Lancet Glob Health 2017;5:e545-55.

15 Akseer N, Salehi AS, Hossain SMM, et al. Achieving maternal and child health gains in Afghanistan: a countdown to 2015 country case study. Lancet Glob Health 2016;4:e395-413.
16 Barbat G, Boigey P, Jehan I. Triple-loop learning : theoretical framework, methodology \& illustration. Proj Proy Proj 2011;8:129-41.

17 Mgawadere F, Kana T, van den Broek N. Measuring maternal mortality: a systematic review of methods used to obtain estimates of the maternal mortality ratio (MMR) in low- and middle-income countries. Br Med Bull 2017;121:121-34.

18 Abouzahr $\mathrm{C}$. New estimates of maternal mortality and how to interpret them: choice or confusion? Reprod Health Matters 2011;19:117-28.

19 UNICEF. Status of civil registration and vital statistics in South Asia countries, 2018. Available: https://www.unicef.org/rosa/reports/ status-civil-registration-and-vital-statistics-south-asia-countries [Accessed 10 Jan 2020].

20 Census of India: sample registration. Available: http://censusindia. gov.in/vital_statistics/SRS/Sample_Registration_System.aspx [Accessed 7 Oct 2019].

21 Graham WJ, Filippi VA, Ronsmans C. Demonstrating programme impact on maternal mortality. Health Policy Plan 1996;11:16-20.

22 Tappis H, Koblinsky M, Doocy S, et al. Bypassing primary care facilities for childbirth: findings from a multilevel analysis of skilled birth attendance determinants in Afghanistan. J Midwifery Womens Health 2016;61:185-95.

23 Ansari N, Tappis H, Manalai P, et al. Readiness of emergency obstetric and newborn care in public health facilities in Afghanistan between 2010 and 2016. Int J Gynaecol Obstet 2020;148:361-8.

24 Ministry of Public Health (APHI/MoPH) [Afghanistan], Central Statistics Organization (CSO), [Afghanistan], ICF Macro, Indian Institute of Health Management Research (IIHMR) [India] and World Health Organization, Regional Office for the Eastern Mediterranean (WHO/EMRO) [Egypt]. Afghanistan mortality survey. Calverton, Maryland, USA, 2010. Available: https://dhsprogram.com/pubs/pdf/ SR186/SR186.pdf [Accessed 7 Oct 2019].

25 KIT Royal Tropical Institute and SRTRO. Afghanistan health survey 2015. Amsterdam, 2017. Available: https://www.kit.nl/wp-content/ uploads/2018/10/08-23-2016-Afghanistan-Health-Survey-2015Final-Report.pdf [Accessed 7 Oct 2019]. 


\section{Correction: Estimating maternal mortality: what have we learned from 16 years of surveys in Afghanistan?}

Alba S, Sondorp E, Kleipool E, et al. Estimating maternal mortality: what have we learned from 16 years of surveys in Afghanistan? BMJ Global Health 2020;5:e002126. doi:10.1136/bmjgh-2019-002126

This article has been corrected since it was published online to reflect two incorrect statements. The errors were in paragraph 3 of Page 2 of the pdf version of the article and pertain to the maternal mortality ratio (MMR) cited from the two RAMOS studies ${ }^{12}$

We revised this sentence "While in a preliminary press release the authors disclosed a national estimate of 1600 deaths per 100,000 live births, ${ }^{9}$ the survey's official publication in 2005 only presented four subnational estimates, ranging from 418 in Kabul to 6507 in Ragh. ${ }^{10}$ to:

The study reported a national estimate of 1600 deaths per 100000 live births and four subnational estimates, ranging from 418 in Kabul to 6507 in Ragh. ${ }^{9,10}$

The second incorrect statement was 'The study showed a large decrease in the MMR, but the enormous MMR decrease especially in Ragh from 6507 in 2002 to 166 in 2011 does cast some doubts on the validity of the RAMOS estimates in general.' It was revised to:

The study showed a large decrease in the MMR, but the MMR decrease in Ragh from 6507 to 713 does cast some doubts on the validity of the RAMOS estimates in general.

\section{REFERENCES}

1. Bartlett LA, Mawji S, Whitehead S, et al. Where giving birth is a forecast of death: maternal mortality in fourdistricts of Afghanistan, 1999-2002. Lancet 2005;365:864-70.

2. Bartlett L, LeFevre A, Zimmerman L, et al. Progress and inequities in maternal mortality in Afghanistan(RAMOS-II): a retrospective observational study. Lancet Glob Health 2017;5:e545-55.

Open access This is an open access article distributed in accordance with the Creative Commons Attribution 4.0 Unported (CC BY 4.0) license, which permits others to copy, redistribute, remix, transform and build upon this work for any purpose, provided the original work is properly cited, a link to the licence is given, and indication of whether changes were made. See: https://creativecommons.org/licenses/by/4.0/.

(C) Author(s) (or their employer(s)) 2022. Re-use permitted under CC BY. Published by BMJ.

BMJ Global Health 2022;7:e002126corr1. doi:10.1136/bmjgh-2019-002126corr1

Check for updates 